\title{
Korean College EFL Learners' Task Motivation in Written Language Production
}

\author{
Bomin $\mathrm{Kim}^{1}$ \& Haedong $\mathrm{Kim}^{2}$ \\ ${ }^{1}$ TESOL (Teaching English to Speakers of Other Languages) Department, Hankuk University of Foreign Studies, \\ Seoul, Korea \\ ${ }^{2}$ Graduate School of Education in Hankuk University of Foreign Studies, Korea \\ Correspondence: Bomin Kim, TESOL (Teaching English to Speakers of Other Languages) Department, Hankuk \\ University of Foreign Studies, Seoul, 107, Imun-ro, Dongdaemun-gu, Seoul, 130-791, Korea. Tel: \\ 82-10-3121-5053. E-mail: b.m.kim.marieanna@gmail.com
}

Received: July 27, 2015 Accepted: August 28, 2015 Online Published: January 25, 2016

doi:10.5539/ies.v9n2p42 URL: http://dx.doi.org/10.5539/ies.v9n2p42

\begin{abstract}
The aims of the present study were to explore the effects of two different types of task conditions (topic choice vs. no choice) on the quality of written production in a second language (lexical complexity, syntactic complexity, and cohesion) and to investigate the effects of these two different task conditions on task motivation. This research was conducted by means of a task motivation questionnaire and a collation of the writings of 31 Korean college students learning English as a foreign language. The data was analyzed using Coh-Metrix 3.0. The major findings were as follows: 1) The writings of participants in the topic choice condition were better than those in the no-choice condition in terms of lexical sophistication and temporal cohesion. However, participants' written production in the no-choice condition was better than that in the topic choice condition in terms of syntactic complexity. 2) The participants' task motivation levels were higher for the perceived choice domain in the topic choice condition than in the no-choice condition. These findings should help L2 writing instructors, materials developers, and researchers to design L2 writing instruction with a focus on written production specifically for Korean college-level learners.
\end{abstract}

Keywords: task motivation, Korean college EFL learners, written English, lexical complexity, syntactic complexity, cohesion, Coh-Metrix

\section{Introduction}

Over the last five decades of SLA research, motivation has received much attention as a central factor in successful language learning (Dörnyei, 2001, 2005; Oxford \& Shearin, 1994; Gardner, Tremblay, \& Masgoret, 1997; Ushioda, 1996, 2001). At present, however, the prevailing conception of motivation has changed from that of a stable construct to that of a situated and dynamic construct (Dörnyei \& Csizér, 1998; Julkunen, 2001; Ma, 2009; Schumann, 1997). Alongside motivation, the important role of "task" has also been considered in the SLA field (Ellis, 2003). The combination of these two phenomena constructs task motivation, which is considered a significant element in its own right in English language learning (ELL) and English language teaching (ELT).

Julkunen (1989) argues that learners' motivation in the context of the language classroom takes two forms: general motivation and task-specific motivation. Recently, several attempts have been made to highlight task-specific motivation in conjunction with language learning (Agnesia, 2010; Dörnyei, 2002; Ma, 2009; Thurman, 2007; Yanguas, 2007). For example, Yanguas (2007) has investigated the relationship between learners' L2 writing performance and task motivation. Kormos (2012) suggests that task motivation in second language writing should be further discussed since there can be a strong link between learners' individual differences and their L2 writing performance.

In their self-determination theory framework (SDT), Deci and Ryan $(1985,2000)$ also note that there are three intrinsic motivational conditions: "autonomy," "competence," and "relatedness." Although studies have recognized SDT in various educational fields, including L2 learning (Ma, 2009; Thurman, 2007), L2 learners' task motivation has not been comprehensively examined in an L2 writing task and by employing an SDT framework. Therefore, the present study employs an SDT framework and focuses closely on the effect of Deci 
and Ryan's $(1985,2000)$ motivational condition of autonomy, using topic choice and no-choice conditions for learners' written work in a Korean college EFL context.

\section{Literature Review}

Post Julkunen's 1989 definition of "task motivation," several studies have been conducted in the three different areas of conversational skills, written production, and online context (Agnesia, 2010; Dörnyei, 2002; Ma, 2009; Thurman, 2007; Yanguas, 2007).

Firstly, focusing on spoken skills, "task motivation" has been investigated in several studies (Dörnyei, 2002; Ma, 2009; Thurman, 2007). Three such studies, by Dörnyei (2002), Ma (2009), and Thurman (2007), showed that if learners have high task motivation, it can lead to a positive effect on their spoken production.

More specifically, Dörnyei (2002) investigated how Hungarian learners' internal and external task motivation was constructed using oral argumentative tasks, and confirmed that there was a strong relationship between language variables and situation-specific variables such as attitude to the task and the course. In particular, Dörnyei (2002) illustrated that there was a significant relationship between the interlocutor and learners' motivation and linguistic variables. In addition, Dörnyei (2002) focused on the interlocutor's "motivational disposition" as a major factor affecting learners' appraisal and action control processes.

Ma (2009) explored Korean learners' task motivation across Deci and Ryan's three different motivational conditions. On an autonomy task, Ma confirmed that there was no significant difference between the topic choice and no-choice conditions. This was attributed to three factors. First, all learners voluntarily participated in the study, all were given alternative activities to the task topic in the no-choice condition, and all participants were Asian learners, who are generally not influenced by lack of choice (Iyengar \& Lepper, 1999). However, Ma (2009) also showed that learners in the choice condition produced more words and turns when speaking. Regarding competitiveness, Ma argued that when learners encourage feedback within their group, they have higher (self-) perceived competence, task motivation, task engagement, and language output than in a group that discourages feedback. With regard to relatedness, Ma (2009) did not find the results anticipated on the basis of Deci and Ryan $(1985,2000)$, in that learners did not show higher levels of perceived relatedness or task motivation in co-operative as compared to competitive tasks, and even showed higher levels of task engagement in the competitive condition. Ma (2009) also argued that further research was needed on L2 learners' task motivation across the four basic language skills (speaking, listening, reading, and writing).

Finally, Thurman (2007) used SDT to investigate Japanese college-level foreign language learners' task motivation using three different types of task-descriptive, narrative, and decision-making — and three different task topic choice conditions-no choice of topic, limited choice of topic, and free choice of topic. Thurman confirmed that learners showed higher levels of task motivation when given a limited choice as compared to a complete choice or no choice. With regard to the interaction between task motivation, task type, and topic choice conditions, Thurman found that learners' task motivation was highest in the narrative-task topic choice condition. On the basis of these findings, Thurman emphasized the importance of curriculum design for the classroom context, as previously suggested by Swain $(1985,1995)$ and Zuckerman et al. $(1978)$. Swain $(1985,1995)$ further argued that language production in a task-based setting might facilitate the learning of a foreign language. In addition, Zuckerman et al. (1978) suggested that if learners are intrinsically motivated, they would take longer to process a task.

To sum up, Ma (2009) suggested that learners produce more speech when given a choice of task or topic, and Thurman (2007) found that learners had higher task motivation and used more language in the narrative task topic choice condition than in two other task types.

Additionally, as far as online learning is concerned, Agnesia (2010) investigated how learners' perceived autonomy, competence, relatedness, and task value have an impact on enjoyment and effort during task completion in online learning contexts. Agnesia concluded by suggesting that according to the quantitative results of her study, autonomy was a predictor of learners' enjoyment, and thus that teachers should use more tasks that support learner autonomy.

Lastly, in terms of written performance, Yanguas (2007) investigated the relationship between learners' task motivation and their written performance based on Dörnyei's process model of motivation. This template divides motivation into "pre-actional (choice motivation), actional (executive motivation), and post-actional (evaluation) phases, $[\ldots]$ each shaped by various internal and contextual motivational influences and regulatory mechanisms" (Ushioda \& Dörnyei, 2011). Yanguas (2007) strongly confirmed a positive correlation between learners' task motivation and written performance with regard to number of words (NW), number of T-units (NTU), and 
lexical variety (LV).

Through the findings of the studies discussed above, it can be concluded that learners' task motivation has a strong impact on their language use across language skills. However, little research has been conducted on task motivation in the field of SLA. Therefore, it will be productive to further study learners' task motivation and autonomy learning conditions, following Kormos (2012), who suggested that learners' task motivation and L2 writing should be studied in more detail.

\section{Method}

\subsection{Participants}

The 31 participants (11 males and 20 females) of the research were Korean college students who were majoring in a range of different disciplines such as Economics, Industrial Engineering, French, Spanish, Chemical Engineering, and so on. They were enrolled in "English Composition" as an elective module and had previously learned English for over 10 years at school. The average self-evaluation scores for English proficiency ranged from 3 to 4 on a scale from 1 to 7 .

\subsection{Research Design and Data Analysis}

All 31 participants were given five minutes to fill out a background information questionnaire in the first week of their English class. Then, participants allocated to the topic choice condition were asked to choose one of two topics for 30 minutes, after which the researcher gave them a task motivation questionnaire to fill out within 10 minutes. The participants allocated to the no-choice condition were asked to write on a given topic for 30 minutes, after which they filled out the questionnaire.

For the analysis, this study used the Coh-Metrix 3.0 program, which is an automated tool for the assessment of writing quality. McNamara and Graesser (2012) argue that the "Coh-Metrix provides indices for the characteristics of texts on multiple levels of analysis, including word characteristics, sentence characteristics, and the discourse relationships between ideas in text" (p. 188). Kormos (2011) also notes that Coh-Metrix gives teachers a linguistic repertoire for the assessment of learners' writing quality and indicates the discourse markers in their writing - more specifically, their lexical complexity, syntactic complexity, and cohesion.

\section{Results}

\subsection{The Effects of Two Task Conditions (Topic Choice vs. No Choice) on Written Production}

To assess the effects of the two task conditions (task choice vs. no choice) on the quality of written production, lexical complexity, syntactic complexity, and cohesion were measured by Coh-Metrix. Tables 1 and 2 present the descriptive statistics of the participants' written production.

Table 1. Descriptive statistics of the linguistic variables

\begin{tabular}{lccc}
\hline & & \multicolumn{2}{c}{ Choices } \\
\cline { 3 - 4 } & $N$ & Task topic choice & Non-topic choice \\
& & M(SD) & M(SD) \\
\hline Lexical complexity & 31 & $39.68(23.37)$ & $38.45(25.73)$ \\
Concreteness & 31 & $.13(.025)$ & $.13(.024)$ \\
Log. Freq. of content words & 31 & $60.75(31.41)$ & $61.54(26.52)$ \\
D-value & 31 & $.60(.08)$ & $.57(.07)$ \\
LDTTRa & 31 & $.67 .17(21.83)$ & $63.36(17.33)$ \\
LDMTLD & & & \\
Syntactic complexity & 31 & $2.01(.87)$ & $2.50(.72)$ \\
Words before main verbs & 31 & $.49(.14)$ & $.50(.13)$ \\
Modifiers per NP & & &
\end{tabular}

Note. $\mathrm{N}=$ Total number of participants, $\mathrm{M}=$ Mean, $\mathrm{SD}=$ Standard deviation, Log. Freq. $=$ Logit frequency, D-value $($ LDVOC $)=$ Lexical diversity measure for all words, LDTTRa $=$ Type token ratio for all words, LDMTLD $=$ Lexical diversity measure for all words. 
Table 2. Descriptive statistics of the different cohesion indices

\begin{tabular}{llcc}
\hline & & \multicolumn{2}{c}{ Choices } \\
\cline { 3 - 4 } & $N$ & Task topic choice & Non-topic choice \\
& & & $\mathrm{M}(\mathrm{SD})$ \\
\hline Causal connectives & 31 & $32.23(16.58)$ & $37.06(17.45)$ \\
Logical connectives & 31 & $48.72(16.50)$ & $56.38(15.42)$ \\
Adversative and & 31 & $14.75(12.73)$ & $16.98(9.51)$ \\
contrastive connectives & & & \\
Temporal connectives & 31 & $17.90(10.80)$ & $16.47(12.37)$ \\
Additive connectives & 31 & $36.68(15.79)$ & $38.73(19.31)$ \\
Referential cohesion & 31 & $49.86(22.47)$ & $53.26(24.73)$ \\
\hline
\end{tabular}

Note. $\mathrm{N}=$ Total number of participants, $\mathrm{M}=$ Mean, $\mathrm{SD}=$ Standard deviation.

As shown in Table 1, the mean of the concreteness index was 39.68, which means the task choice condition encouraged participants to use more abstract words in general compared to the no-choice condition (38.45). Comparing the content word overlap index, participants also used more meaningful words in the task choice condition (Log. Freq. of content words: .025). In addition, the task choice condition helped participants to increase their lexical diversity, as indicated by the LDTTRa (.60) and LDMTLD (.67), to a greater extent than under the no-choice condition (LDTTRa: .57, LDMTLD: .63). From the data regarding the temporal connectives index (17.90) in Table 2, it seems that participants wrote more coherent texts in the task choice condition compared to the no-choice condition (16.47).

Overall, the no-choice condition encouraged participants to produce more syntactically complex text and to use more words before the main verb than in the task choice condition. Participants in the no-choice condition also produced more coherent text in terms of causal, logical, adversative and contrastive, and additive connectors than in the task choice condition. The results in Table 2 indicate that referential cohesion was higher in the no-choice condition (53.26) than in the task choice condition (49.86).

To determine if these differences between the effects of the task choice condition and the no-choice condition on participants' written production were statistically significant, a paired-sample t-test was conducted. The results, as displayed in Table 3, reveal significant differences between conditions in syntactic complexity as indicated by the SYNLE index and words before the main verb $(\mathrm{t}=-2.36, \mathrm{p}<.05)$ and lexical diversity as indicated by LDTTRa $(\mathrm{t}=2.45, \mathrm{p}<.05)$. 
Table 3. T-test results for the difference between the task choice condition and no-choice condition

\begin{tabular}{lccccc}
\hline & $\mathrm{M}$ & $\mathrm{SD}$ & $\mathrm{t} *$ & $\mathrm{df}$ & Sig. \\
\hline Lexical complexity & & & & & \\
Concreteness & 1.22 & 22.07 & .31 & 30 & .75 \\
Log. Freq. of content words & .00 & .02 & .13 & 30 & .89 \\
D-value & -.78 & 24.64 & -.17 & 30 & .86 \\
$\quad$ LDTTRa & .03 & .07 & 2.45 & 30 & $.02^{*}$ \\
$\quad$ LDMTLD & 3.80 & 19.42 & 1.09 & 30 & .28 \\
Syntactic complexity & & & & & \\
Words before main verbs & -.48 & 1.15 & -2.36 & 30 & $.02 *$ \\
Modifiers per NP & -.00 & .20 & -.17 & 30 & 86 \\
Cohesion & & & & & \\
Causal connectives & -4.82 & 23.78 & -1.12 & 30 & .26 \\
Logical connectives & -7.66 & 24.19 & -1.76 & 30 & .08 \\
Adversative and contrastive & -2.23 & 14.21 & -.87 & 30 & .38 \\
connectives & & & & & .57 \\
Temporal connectives & 1.43 & 14.24 & .56 & 30 & .99 \\
Additive connectives & -.04 & 23.00 & -.01 & 30 & .46 \\
Referential cohesion & -3.40 & 25.53 & -.74 & 30 & \\
\hline
\end{tabular}

* Significance threshold at the $\mathrm{p}<.05$ level.

\subsection{The Effects of Task Conditions on Task Motivation}

As can be seen in Table 4, in the perceived choice domain, the participants' task motivation showed higher mean scores in the task choice condition $(\mathrm{M}=4.76)$ than in the no-choice condition $(\mathrm{M}=4.14)$. In the intrinsic motivation domain, the participants' task motivation showed higher means in the no-choice condition $(\mathrm{M}=4.32)$ than in the task choice condition $(\mathrm{M}=4.26)$. In the identified regulation domain, task motivation showed higher mean scores in the task choice condition $(\mathrm{M}=5.35)$ than in the no-choice condition $(\mathrm{M}=5.24)$. In the external regulation domain, mean task motivation was higher in the task choice condition $(\mathrm{M}=5.34)$ than in the no-choice condition ( $\mathrm{M}=5.32)$. In the amotivation domain, mean task motivation was higher in the task choice condition $(M=2.99)$ than in the no-choice condition $(M=2.76)$. Finally, in the intention to persist domain, mean task motivation was higher in the no-choice condition $(M=4.79)$ than in the task choice condition $(M=4.63)$.

Table 4. Participants' task motivation in the perceived choice domain

\begin{tabular}{lcc}
\hline Domain & $\begin{array}{c}\text { Task topic choice } \\
\mathrm{M}(\mathrm{SD})\end{array}$ & Non-topic choice M(SD) \\
\hline Perceived choice & $4.76(1.73)$ & $4.14(1.67)$ \\
Intrinsic motivation & $4.26(1.48)$ & $4.32(1.47)$ \\
Identified regulation & $5.35(1.29)$ & $5.24(1.35)$ \\
External regulation & $5.34(1.43)$ & $5.32(1.39)$ \\
Amotivation & $2.99(1.32)$ & $2.76(1.30)$ \\
Intention to persist & $4.63(1.41)$ & $4.79(1.43)$ \\
\hline
\end{tabular}

Note. $\mathrm{M}=$ Mean. $\mathrm{SD}=$ Standard deviation. 
To discover whether there was any significant difference between the task choice condition and the no-choice condition on the task motivation scale, a paired-sample t-test was conducted. The results revealed a significant difference between conditions in the perceived choice domain $(t=-3.34, \mathrm{p}<.05)$ as displayed in Table 5 .

Table 5. T-test Results for the difference between the task choice condition and no-choice condition on task motivation

\begin{tabular}{lccccc}
\hline & $\mathrm{M}$ & $\mathrm{SD}$ & $\mathrm{t}^{*}$ & $\mathrm{df}$ & Sig. \\
\hline Perceived choice & -.62 & 2.07 & -3.34 & 12 & $.00^{*}$ \\
Intrinsic motivation & .06 & 1.83 & .43 & 15 & .66 \\
Identified regulation & -.10 & 1.47 & -.92 & 15 & .35 \\
External regulation & -.02 & 1.56 & -.13 & 92 & .89 \\
Amotivation & -.22 & 1.51 & -1.85 & 15 & .06 \\
Intention to persist & .15 & 1.91 & .89 & 12 & .37 \\
\hline
\end{tabular}

* Significance threshold at the $\mathrm{p}<.05$ level.

\section{Discussion}

Ellis and Beaton (1993) note that the word "meaningfulness" is related to the priming effect of words. In light of this, the results of the current study have shown that the task choice condition had more effect on participants' written performance, increased their ability to recall, and activated other associated words. Kormos (2011) reports that a picture narrative task induced participants to write more lexically sophisticated text than a cartoon narrative task. On this basis, she suggests that when learners are given more freedom (more choice) in a writing task, it might increase their motivation and improve the organization of their texts. We also found that if learners were under a task condition in which they could choose their writing topic, they might be more intrinsically motivated and therefore might produce better writing than those in the no-choice condition. These results are very similar to the claims made by Kormos (2011) as well as by Deci and Ryan's $(1985,2000)$ self-determination theory.

The results of this study also show that a considerable difference in syntactic complexity does exist between the task choice condition and the no-choice condition. There are several possible explanations for the results. As Iyengar and Lepper (1999) mention choice may not be an important motivating element for Asian-American students but may be for Anglo-American students. In other words, Asian-American students like their choices to be made by teachers unlike Anglo-American students. Therefore, it may have been more difficult to choose a written topic for the Korean students because of their cultural background. This is mainly because many Korean students have been given tasks that they are expected to complete, following teachers' instructions at school right up through high school. However, these results need to be interpreted with caution since "Asianness" cannot always be relied upon as a factor and students may have their own reasons or views on the tasks.

There was no specific word limit for participants' written texts in this experiment. This might have affected the syntactic complexity of the texts. Participants might have written longer texts in the no-choice condition than in the task choice condition because of the cultural context mentioned by Iyengar and Lepper (1999) in explaining the high syntactic complexity in this condition. Another important issue is that choosing a topic can be cognitively demanding for Korean students when completing tasks, especially under experimental conditions. In the current study, Korean learners in the topic choice group had to read two topics, and carefully consider which was more familiar or which they would like to write on before making a choice. These cognitive and logical processes might have been challenging for the participants.

In terms of writing strategies, the cognitive process that occurs between thinking and the final text process remains unclear. However, Galbraith (2009) notes that "strategies for managing the writing process which help reduce cognitive load should also enable more effective planning" (p. 12). In a similar vein, Kellogg (1988) examines the effects of different drafting strategies in a series of experiments and finds a positive effect on language production. In other words, it appears that writing instructors should focus on helping learners to become more familiar with various types of writing strategy, including Kellogg's (1988, 1990, 1994) useful outlining strategies to decrease cognitive overload and help with effective planning. 
According to the descriptive statistics yielded by the data, the 31 participants' written production showed greater cohesion in the no-choice condition than in the task choice condition, as measured by causal connectives, logical connectives, adversative and contrastive connectives, and additive connectives. This was very similar to the findings of Kormos's (2011) study, which showed that all participants in both non-native and native groups used fewer connectives in picture narrative tasks than in cartoon narrative tasks. She reports that the reason for this phenomenon was that learners might have difficulty using various connectives when they were supposed to construct all of the content during the writing process. As far as the effects of the two task choice conditions on task motivation are concerned, there was significantly stronger task motivation in the task choice condition as compared to the no-choice condition in the perceived choice domain. This finding appears to be in line with previous empirical research (Ma, 2009) that suggests that participants in the choice condition have higher levels of perceived choice than those in the no-choice condition.

\section{Conclusion}

This study has attempted to investigate the existing research on the effects of two different choice conditions in a writing task (choice vs. no-choice) for Korean EFL college learners' task motivation. The results showed that the task choice condition induced participants to use more abstract words, meaningful words, lexically diverse words, and temporal connectives than the no-choice condition. In the meantime, the no-choice condition induced participants to use more syntactically complicated text and more causal, logical, adversative, and contrastive, and additive connectors than the task choice condition. Referential cohesion was also higher in the no-choice condition. Regarding the effects on task motivation, this study found a significant difference between the task choice condition and no-choice condition in the perceived choice domain of motivation.

However, this study considered only the autonomy condition among the three conditions of Deci and Ryan's self-determination theory $(1985,2000)$. In other words, further work should be carried out in order to investigate the effects of task conditions on all three motivational conditions of "autonomy," "competence," and "relatedness," in terms of learners' L2 written production. Another weak point concerns the t-test results for learners' written production. Some evidence suggests a significant difference in syntactic complexity between the task choice condition and the no-choice condition, for which three tentative reasons were put forward: learners' cultural background, lack of word limits in the experimental conditions, and high cognitive demands associated with choosing a topic in the task choice condition. In further research, more research on the specific reasons why participants' writing was more complex under the no-choice condition needs to be undertaken.

Despite these limitations, this study has provided some important insights into the complicated connections between L2 written performance, task motivation, and task choice (or lack thereof) from a self-determination theory perspective, and provided some potential ideas for future studies.

\section{Acknowledgments}

This research is financed by Hankuk University of Foreign Studies Research Fund of 2015.

\section{References}

Agnesia, R. H. (2010). Features affecting task motivation in English for academic purposes online learning. Second Language Studies, 29(1), 1-34.

Deci, E. L., \& Ryan, R. M. (1985). Intrinsic motivation and self-determination in human behavior. New York: Plenum. http://dx.doi.org/10.1007/978-1-4899-2271-7

Deci, E. L., \& Ryan, R. M. (2000). The 'what' and 'why' of goal pursuits: Human needs and the self-determination of behaviour. Psychological Inquiry, 11(4), 227-268. http://dx.doi.org/10.1207/S15327965PLI1104_01

Dörnyei, Z. (2001). Teaching and researching motivation. Harlow, UK: Longman.

Dörnyei, Z. (2002). The motivational basis of language learning tasks. In P. Robinson (Ed.), Individual differences and instructed language learning (pp. 137-158). Philadelphia: John Benjamins.

Dörnyei, Z. (2005). The psychology of the language learner: Individual differences in second language acquisition. Mahwah, NJ: Lawrence Erlbaum.

Dörnyei, Z., \& Csizér, K. (1998). Ten commandments for motivating language learners: Results of empirical study. Language Teaching Research, 2, 203-229. http://dx.doi.org/10.1177/136216889800200303

Ellis, N., \& Beaton, A. (1993). Factors affecting the learning of foreign language vocabulary: Imagery keyword mediators and phonological short term memory. The Quarterly Journal of Experimental Psychology, 46A, 


\section{3-558. http://dx.doi.org/10.1080/14640749308401062}

Ellis, R. (2003). Task-based language learning and teaching. Oxford, UK: Oxford University Press.

Galbraith, D., \& Trent, S. (2009). Cognitive models of writing. GFL-Journal, 2-3, 7-22.

Gardner, R. C., Tremblay P. F., \& Masgoret A. M. (1997). Toward a full model of second language learning: An empirical investigation. Modern Language Journal, 81, 344-362. http://dx.doi.org/10.1111/j.1540-4781.1997.tb05495.x

Iyengar, S., \& Lepper, M. (1999). Rethinking the value of choice: A cultural perspective on intrinsic motivation. $\begin{array}{lllll}\text { Journal of Personality and Social Psychology, 76(3), 349-366. } & \text {. }\end{array}$ http://dx.doi.org/10.1037/0022-3514.76.3.349

Julkunen, K. (1989). Situation- and task-specific motivation in foreign-language learning and teaching. Joensuu, Finland: University of Joensuu Publications in Education.

Julkunen, K. (2001). Situation- and task-specific motivation in foreign language learning. In Z. Dörnyei, \& R. Schmidt (Eds.), Motivation and second language acquisition (pp. 29-41). Honolulu: University of Hawaii, Second Language Teaching and Curriculum Center.

Kellogg, R. T. (1988). Attentional overload and writing performance: Effects of rough draft and outline strategies. Journal of Experimental Psychology: Learning, Memory, and Cognition, 14(2), 355-365. http://dx.doi.org/10.1037/0278-7393.14.2.355

Kellogg, R. T. (1990). Effectiveness of prewriting strategies as a function of task demands. American Journal of Psychology, 103, 327-342. http://dx.doi.org/10.2307/1423213

Kellogg, R. T. (1994). The psychology of writing. Oxford, UK: Oxford University Press.

Kormos, J. (2011). Task complexity and linguistic and discourse features of narrative writing performance. Journal of Second Language Writing, 20(2), 148-161. http://dx.doi.org/10.1016/j.jslw.2011.02.001

Kormos, J. (2012). The role of individual differences in L2 writing. Journal of Second Language Writing, 21, 390-403. http://dx.doi.org/10.1016/j.jslw.2012.09.003

Ma, J. H. (2009). Autonomy, competence, and relatedness in L2 students' task motivation: A self-determination theory perspective (Unpublished doctoral dissertation). University of Hawaii, Honolulu.

McNamara, D. S., \& Graesser, A. C. (2012). Coh-Metrix: An automated tool for theoretical and applied natural language processing. In P. M. McCarthy, \& C. Boonthum (Eds.), Applied natural language processing and content analysis: Identification, investigation, and resolution (pp. 188-205). Hershey, PA: IGI Global.

Oxford, R., \& Shearin, J. (1994). Language learning motivation: Expanding the theoretical framework. The Modern Language Journal, 78, 12-28. http://dx.doi.org/10.1111/j.1540-4781.1994.tb02011.x

Schumann, H. J. (1997). The neurobiology of affect in language. Malden, MA: Blackwell Publishers Ltd.

Swain, M. (1985). Communicative competence: Some roles of comprehensible input and comprehensible output in its development. In S. Gass, \& C. Madden (Eds.), Input in second language acquisition (pp. 235-252). Rowley, MA: Newbury House.

Swain, M. (1995). Three functions of output in second language learning. In G. Cook, \& B. Seidlhofer (Eds.), Principles and practice in applied linguistics (pp. 125-144). Oxford, UK: Oxford University Press.

Thurman, J. (2007). Choice of task topic: Are the students more motivated? In K. Bradford-Watts (Ed.), JALT 2006 Conference Proceedings (pp. 12-24). Tokyo: Japan Association for Language Teaching.

Ushioda, E. (1996). Developing a dynamic concept of motivation. In T. Hickey, \& J. Williams (Eds.), Language, education and society in a changing world (pp. 239-245). Clevedon, UK: Multilingual Matters.

Ushioda, E. (2001). Language learning at university: Exploring the role of motivational thinking. In Z. Dörnyei, \& R. Schmidt (Eds.), Motivation and second language acquisition (pp. 461-492). Honolulu: University of Hawaii Second Language Teaching and Curriculum Center.

Yanguas, I. A. (2007). A look at second language learners' task motivation. In I. Barbería, R. Campos-Astorkiza, \& S. Huidobro (Eds.), Proceedings of BIDE 2005 (pp. 333-345). Leioa, Spain: University of the Basque Country.

Zuckerman, M., Porac, J., Lathin, D., Smith, R., \& Deci, E. L. (1978). On the importance of self-determination for intrinsically-motivated behavior. Personality and Social Psychology Bulletin, 4(3), 443-446. 
http://dx.doi.org/10.1177/014616727800400317

\section{Copyrights}

Copyright for this article is retained by the author(s), with first publication rights granted to the journal.

This is an open-access article distributed under the terms and conditions of the Creative Commons Attribution license (http://creativecommons.org/licenses/by/3.0/). 